\title{
International collaborative study to evaluate and calibrate two recombinant $L$ chain Ferritin preparations for use as a WHO International Standard
}

https://doi.org/10.1515/cclm-2021-1139

Received October 25, 2021; accepted December 5, 2021; published online December 17, 2021

\section{Abstract}

Objectives: To evaluate and calibrate two candidate preparations for the 4th International Standard for Ferritin (Human, Recombinant) (codes: 19/118 and 19/162) against the 3rd International Standard for Ferritin (Human, Recombinant) (code: 94/572), and three serum commutability samples in an international collaborative study involving 12 laboratories in nine countries.

Methods: Eleven of the 12 participating laboratories performed Ferritin quantitation using automated assay platforms and one laboratory used a manual ELISA kit.

Results: There was better overall agreement between all laboratories and between assay methods for the potency of preparation 19/118 than for preparation 19/162. The overall geometric mean potency (from all methods) of the candidate 4th International Standard, 19/118, was $10.5 \mu \mathrm{g} /$ ampoule, with inter-laboratory variability, expressed as \% geometric coefficient of variation (GCV), of 4.7\%. Accelerated stability studies have predicted both $19 / 118$ and $19 / 162$ to be very stable for long term storage at $-20^{\circ} \mathrm{C}$.

Conclusions: The candidate 4th International Standard for Ferritin (Human, Recombinant) (19/118) has been shown to be immunologically similar to the 3rd International

Work conducted at the National Institute for Biological Standards and Control (NIBSC).

*Corresponding author: Bernard Fox, Biotherapeutics Division, National Institute for Biological Standards and Control, Blanche Lane, South Mimms, Potters Bar, Hertfordshire, EN6 3QG, UK,

Phone: +44 (0) 1707 641476, E-mail: Bernard.Fox@nibsc.org. https://orcid.org/0000-0001-6362-5196

Graham Roberts and Christina Ball, Biotherapeutics Division, National Institute for Biological Standards and Control, Hertfordshire, UK

Eleanor Atkinson and Peter Rigsby, Division of Analytical and Biological Sciences, National Institute for Biological Standards and Control, Hertfordshire, UK

Ә Open Access. () 2021 Bernard Fox et al., published by De Gruyter. (co)BY International License.
Standard for Ferritin (Human, Recombinant) (94/572). It was recommended to and accepted by the WHO Expert Committee on Biological Standardization that 19/118 be established as the 4th International Standard for Ferritin (Human, Recombinant) with an assigned potency of $10.5 \mu \mathrm{g} /$ ampoule and expanded uncertainty limits 10.2-10.8 $\mu \mathrm{g}$ /ampoule (95\% confidence; $k=2.23$ ).

Keywords: anaemia; immunoassay; International Standard; iron; serum Ferritin.

\section{Introduction}

Ferritin is the main storage protein for iron in tissues and is engaged in its uptake, accumulation and release in cells. The Ferritin molecule is a heterogenous (made up varying proportions of $\mathrm{H}$ and $\mathrm{L}$ subunits) intracellular hollow protein shell composed of 24 subunits surrounding an iron core that may contain as many as 4,000-4,500 iron atoms. The regulation of Ferritin iron storage has recently been reviewed by Arosio et al. [1].

Circulating Ferritin is normally predominantly in the $\mathrm{L}$ subunit form and is not iron-bearing. The level of serum Ferritin directly reflects the level of stored iron and is normally quantified using an antibody test, that detects the Ferritin protein, to diagnose iron-related disorders, in surveys of iron status and as a marker for inflammation [2]. See Worwood [3, 4] and World Health Organization (WHO) [5] for reviews of serum Ferritin. The WHO have also recently revised their global guidelines for the use of Ferritin thresholds in patient groups with iron deficiency and those at risk of iron overload [6].

To help standardize results from different assay methodologies, WHO International Standards (IS) have been prepared using Ferritin derived from human liver and spleen tissue [7-9]. Due to difficulties in acquiring suitable tissue the current 3rd IS was prepared using a recombinant L chain which was shown to be immunologically similar to the 2nd IS derived from spleen [10]. The 3rd IS, in use since 1997, has been distributed to more than 200 companies in 
38 countries and stocks are almost depleted. For this study we have produced candidate preparations of recombinant Ferritin L chain (FLC) (Supplementary Figure 1) expressed in $E$. coli and Chinese hamster ovary (CHO) cells and subjected the materials to an international collaborative study. The results of the international collaborative study to replace the 3rd IS for Ferritin are presented in this article.

\section{Materials and methods}

\section{Materials for the collaborative study}

The codons for human FLC were separately optimized for bacterial and mammalian expression, cloned into pET-21a for E. coli BL21 (DE3) expression or pcDNA ${ }^{\mathrm{TM}} 3.4$ for ExpiCHO-S ${ }^{\mathrm{TM}}$ expression (Supplementary Figure 2) and the sequences verified by Sanger sequencing. FLC was expressed in each cell type following the manufacturer's instructions \{pET-21a(+) DNA - Novagen (merckmillipore.com), MAN0014337_expicho_expression_system.pdf (thermofisher.com)\} and the cell pellets harvested by centrifugation. E. coli cell pellets were lysed, on ice, with $1 \%$ Lysozyme (Merck, Dorset, UK) and 0.1\% Benzonase nuclease (Merck, Dorset, UK) in PBS, sonicated (Soniprep 150, Henderson Biomedical, London, UK) and the supernatant containing the crude FLC extract isolated by centrifugation. ExpiCHO- ${ }^{\mathrm{TM}}$ cell pellets were lysed in ice cold deionized water containing $0.1 \%$ Benzonase nuclease (Merck, Dorset, UK) and the supernatant containing the crude FLC extract again isolated by centrifugation. Both crude FLC extracts were further purified as described by Levi et al. [11, 12], dialyzed into PBS, aliquoted $(1 \mathrm{~mL}$ at $6 \mathrm{mg} / \mathrm{mL})$, stored at $-80^{\circ} \mathrm{C}$ and thawed in a water bath at $+37^{\circ} \mathrm{C}$ prior to lyophilization or further analysis. The purified FLC amino acid sequence from both expression systems was confirmed by liquid chromatography with tandem mass spectrometry (LC-MS/MS) using Swiss-Prot for data analysis. The concentrations of the purified FLC preparations were determined by immunoassay using the 3rd IS as the assay calibrant. Three commutability (clinical) serum samples containing low, normal and high levels of Ferritin were purchased from the Wales External Quality Assurance Scheme (WEQAS) and stored at $-80^{\circ} \mathrm{C}$ prior to lyophilization.

Participants were allocated three ampoules of each of the coded materials shown in Table 1.

Sample A consisted of FLC expressed in E. coli BL21 (DE3) transformed with plasmid pET-21a containing the full FLC sequence. At the National Institute for Biological Standards and Control (NIBSC), purified FLC protein was diluted to $\sim 10 \mu \mathrm{g} / \mathrm{mL}$ in human serum (TCS Biosciences, Buckingham, UK) containing $40 \mathrm{mM}$ HEPES (Merck, Dorset, UK) and $1 \%$ Trehalose (Merck, Dorset, UK), dispensed into ampoules ( $1 \mathrm{~mL} /$ ampoule), lyophilized and coded 19/118. The mean weight of the dispensed solution in 220 ampoules was $1.0089 \mathrm{~g}$. The imprecision of the filling $(\mathrm{CV})$ was $0.171 \%$, and the residual moisture was $0.38 \%$. Sample B consisted of FLC expressed in ExpiCHO-S ${ }^{\mathrm{TM}}$ cells transfected with Plasmid pcDNA ${ }^{\mathrm{TM}} 3.4$ containing the full FLC sequence. At the NIBSC purified FLC protein was diluted to $\sim \mu \mathrm{g} / \mathrm{mL}$ in human serum containing $40 \mathrm{mM}$ HEPES and $1 \%$ Trehalose, dispensed into ampoules ( $\sim \mathrm{mL} /$ ampoule), lyophilized and coded 19/162. The mean weight of the dispensed solution in 143 ampoules was $1.0094 \mathrm{~g}$. The imprecision of the filling (CV) was $0.160 \%$, and the

Table 1: Lyophilized Ferritin preparations provided in the collaborative study.

\begin{tabular}{ll}
\hline Code & Preparation \\
\hline Sample S & $\begin{array}{l}\text { WHO 3rd International Standard for Ferritin, human } \\
\text { recombinant (lyophilized; } 94 / 572) . \\
\text { Contents: } 6.3 \mu \mathrm{g} / \text { ampoule. } \\
\text { Lyophilized recombinant Ferritin in serum } \\
(19 / 118) . \text { Contents: approximately } 10 \mu \mathrm{g} / \text { ampoule. } \\
\text { Sample A }\end{array}$ \\
Sample B & $\begin{array}{l}\text { Lyophilized recombinant Ferritin in serum } \\
\text { Lyophilized high serum Ferritin. Contents: }\end{array}$ \\
Sample C & $\begin{array}{l}\text { approximately 0.9 } \mu \mathrm{g} / \text { ampoule. } \\
\text { Lyophilized normal serum Ferritin. Contents: }\end{array}$ \\
Sample D & $\begin{array}{l}\text { approximately } 0.1 \mu \mathrm{g} / \text { ampoule. } \\
\text { Lyophilized low serum Ferritin. Contents: } \\
\text { approximately } 0.01 \mu \mathrm{g} / \text { ampoule. }\end{array}$ \\
\hline
\end{tabular}

residual moisture was $0.42 \%$. Samples C, D and E consisted of human serum from patients with high, normal and low levels of Ferritin respectively. At the NIBSC the serum samples were formulated with the addition of $40 \mathrm{mM}$ HEPES and 1\% Trehalose, prior to dispensing into ampoules ( 1 mL/ampoule) and lyophilization. The mean weight of the dispensed solutions in 9 ampoules was $1.0285 \mathrm{~g}$. The imprecision of the filling (CV) was $0.130 \%$, and the residual moisture was $0.15 \%$. Note, samples C, D and E were only for distribution in the collaborative study. Samples D and E are intended to be assayed neat.

For all samples the sera were tested and found negative for antiHIV, anti-HCV, HCV RNA and HBsAg.

\section{Participants}

A total of 15 laboratories in 10 countries across the globe agreed to participate in the study, 12 laboratories from nine countries returned results (detailed in Table 2), each of which has been assigned a code number. This coding does not reflect the order of listing.

Table 2: Participants of the collaborative study (in alphabetical order of country).

Ian Higgins

Ulla Määttä

Roland Knauer

Susanne Feldmann,

Silke Luebcke

Harald Althaus

Vasilis Tsaousis

JiYoon Kim, Elaine

O'Doherty

Hisao Tsukamoto

Goran Brattsand

Paul Pettersson-Pablo

Graham Roberts, Bernard Fox

Ryan Masica
Diagnostics Biochem Canada Inc., Canada Thermo Fisher Scientific Oy, Finland Human Gesellschaft für Biochemica und Diagnostica mbH, Germany

Roche Diagnostics, Germany

Siemens Healthcare Diagnostics Products GmbH, Germany Medicon Hellas SA, Greece

Abbott Ireland Diagnostic Division, Ireland

Tosoh Corporation, Japan

Clinical Chemistry, NUS, Sweden

Clinical Chemistry, Örebro University

Hospital, Sweden

NIBSC, UK

Beckman Coulter, USA 


\section{Ferritin quantitation methods}

A WHO International Standard should be suitable for use in as many different assay methods as possible. Therefore, all participating laboratories were requested to perform their usual method of analysis (Table 3). Where a laboratory performed more than one assay method, or an additional variation of the same assay method, each was treated as if performed by different laboratories.

\section{Study design}

Each participant was provided with a protocol and three ampoules of each study samples (A-E) detailed above. For each assay method, participants were requested to perform two assays on each of three days resulting in six assay estimates for each study sample relative to their in-house calibrant. Regardless of the assay method used, participants were requested to prepare two independent sets of fresh dilutions using their usual assay diluent to fall within the measurable range of their assay for each preparation in each assay run.

Raw assay data including pre-dilutions and dilutions were requested together with a summary of the participants' own estimates of potency for the six Ferritin samples.

\section{Statistical analysis}

The potencies of coded samples A-E were calculated relative to the 3rd International Standard, 94/572. Individual assay potency estimates

Table 3: Instruments and assay test kits used in the collaborative study and WHO IS used to calibrate the corresponding in-house standard.

\begin{tabular}{|c|c|}
\hline $\begin{array}{l}\text { Instruments/assay platform } \\
\text { used in the collaborative study } \\
\text { (in alphabetical order) }\end{array}$ & $\begin{array}{l}\text { In-house standard calibrated } \\
\text { using }\end{array}$ \\
\hline Abbott Architect iSR2000 & 1st IS (80/602) \\
\hline $\begin{array}{l}\text { Beckman Coulter Access } \\
\text { Immunoassay }\end{array}$ & 3rd IS $(94 / 572)$ \\
\hline $\begin{array}{l}\text { Beckman Coulter Olympus AU400 } \\
\text { using Medicon Ferritin test kit }\end{array}$ & 3rd IS $(94 / 572)$ \\
\hline $\begin{array}{l}\text { DBC Sandwich ELISA using the Tecan } \\
\text { Infinite F50 ELISA absorbance } \\
\text { microplate reader }\end{array}$ & 3rd IS $(94 / 572)$ \\
\hline $\begin{array}{l}\text { DiaSorin Liaison XL sandwich } \\
\text { chemiluminescence immunoassay }\end{array}$ & 2nd IS (80/578) \\
\hline Human Huma CLIA150 immunoassay & $\begin{array}{l}\text { 2nd IS }(80 / 578) \text { and evaluated } \\
\text { against 3rd IS (94/572) with } \\
\text { acceptable recovery }\end{array}$ \\
\hline Roche Cobas e601 using Elecsys ${ }^{\circledR}$ & 1 st IS $(80 / 602)$ with estab- \\
\hline Ferritin test kit & $\begin{array}{l}\text { lished traceability to } 3 \text { rd IS } \\
(94 / 572)\end{array}$ \\
\hline Roche Cobas e801 (CobasPro) using & 1 st IS $(80 / 602)$ with estab- \\
\hline Elecsys ${ }^{\circledR}$ Ferritin test kit & $\begin{array}{l}\text { lished traceability to 3rd IS } \\
(94 / 572)\end{array}$ \\
\hline $\begin{array}{l}\text { Siemens Advia Centaur XPT using } \\
\text { Advia Centaur Ferritin test kit }\end{array}$ & 2nd IS (80/578) \\
\hline Siemens BNII System N latex Ferritin & 3rd IS $(94 / 572)$ \\
\hline Thermo Fisher Scientific Indiko & 3 rd IS $(94 / 572)$ \\
\hline Tosoh AIA-2000 & 1st IS (80/602) \\
\hline
\end{tabular}

were calculated using parallel line analysis with a log transformation of assay response. Calculations were performed using the R software program [13]. Non-linearity and non-parallelism of dose-response relationships were considered in the assessment of assay validity. Linearity was assessed by calculating the coefficient of determination $\mathrm{R}^{2}$ and parallelism was assessed by calculation of the ratio of fitted slopes for the test and reference sample. Instances where the $\mathrm{R}^{2}$ value was $<0.99$, or where the ratio of fitted slopes was outside the range $0.90-1.11$, were considered invalid and no estimates were reported in such cases.

Results from all valid assays were combined to generate unweighted geometric mean (GM) estimates for each laboratory and these laboratory means were used to calculate overall unweighted geometric means for each sample. Variability between assays (within laboratories) and between laboratories has been expressed using the geometric coefficient of variation $\left(\mathrm{GCV}=\left\{10^{\mathrm{s}}-1\right\} \times 100 \%\right.$ where $s$ is the standard deviation of the $\log _{10}$ transformed estimates).

Individual assay estimates of relative potencies were log transformed and a variance components analysis was performed in order to determine the intra-lab and inter-lab components of variation. These were used to determine standard uncertainty estimates for samples A (19/118) and B (19/162). The expanded uncertainty was obtained by multiplying the standard uncertainty by the coverage factor $k=2.23$, taken to correspond to a $95 \%$ level of confidence.

\section{Stability}

To predict stability on extended storage, ampoules of samples A $(19 / 118)$ and $B(19 / 162)$ were stored at elevated temperatures $(+4,+20$, $+37,+45$ and $+56^{\circ} \mathrm{C}$ ) in temperature mapped equipment for longer than one year before analysis. The relative potencies of the accelerated thermal degradation samples were used to fit an Arrhenius equation relating degradation rate to absolute temperature assuming first-order decay [14], and hence predict the degradation rates when stored at a range of temperatures.

\section{Results}

\section{Assay data}

The 12 participants contributed data from a total of 75 assays, deviations from the study protocol and other anomalies were as follows: (i) Laboratory 5 provided two data sets from separate operators. (ii) Laboratory 9 reported results from one assay on each of three days due to staff shortage.

\section{Assay validity}

The majority of assays gave valid potency estimates when assessed using the validity criteria described in Statistical analysis, which were intended for use in the analysis of data from this study only and should not be interpreted as suitable for routine use in the assessment of assay validity within all collaborating laboratories. Around $10 \%$ of cases were excluded due to non-linearity or non-parallelism. 
Where the number of valid assays was less than three $(\mathrm{n}<3)$ a GCV was not calculated.

\section{Laboratory reported potencies and potencies relative to the WHO 3rd International Standard for Ferritin (Human Recombinant), $94 / 572$}

Potency estimates from individual assays for each laboratory, calculated by the NIBSC and reported by the laboratories are respectively presented in Supplementary Tables 1 and 2. Details of the individual laboratory geometric mean (GM) potencies of samples S, A-E based on laboratory reported estimates are shown in Table 4. Individual laboratory GM potencies of samples A-E relative to sample $S$, the 3rd IS for Ferritin (Human Recombinant) based on the NIBSC calculated estimates are shown in Table 5. For some manufacturers, the IS used to calibrate an assay test kit varies dependent on the region where the assay test kit is marketed. Seven of the 12 laboratories use the 3rd IS for Ferritin (Human, Recombinant) to calibrate their test kits directly or indirectly, with the remaining five laboratories claiming traceability to either the 1st or 2nd IS for Ferritin (see Table 3 for details). The GM laboratory reported results and GM NIBSC calculated results relative to sample $\mathrm{S}$ are presented as histograms in Figure 1A-K. Based on an overall normal serum Ferritin concentration range of 15-200 ng/mL [5], all participating laboratories identified commutability (clinical) samples C, D and E as containing high, normal, and low levels of Ferritin respectively.

\section{Intra-laboratory variability}

For laboratory reported results, GCV's ranged from 0.4 to $7.2 \%$ (median 2.8\%) for samples S, A and B; 0.5-10.1\% (median 2.6\%) for commutability samples $\mathrm{C}$ and $\mathrm{D}$ and 2.0-21.7\% (median 6.6\%) for commutability sample E (Table 4). Using the NIBSC calculations relative to sample S (Table 5), GCV's for samples A and B were $\leq 5 \%$ (representing good repeatability); ranged from 1.1 to $13.1 \%$ (median 3.9\%) for commutability samples $\mathrm{C}$ and D and 1.2-42.8\% (median 11.3\%) for commutability sample E. Sample E is below the limit of quantitation (LoQ) for the dilution series used for samples $\mathrm{S}, \mathrm{A}$ and $\mathrm{B}$, thereby contributing to the higher intra-laboratory variability for this sample. For three laboratories (08, 09 and 10) no \% GCV's were available for one or more samples due to insufficient valid assays.

\section{Inter-laboratory variability}

Inter-laboratory variability is much improved when potencies for samples $A$ and $B$ are determined relative to the 3rd IS for Ferritin (Human Recombinant) as shown in Table 5 and histograms in Figure 1B-E. Inter-laboratory variability is greater for clinical (heterogeneous) samples C-E which is reduced to around $20 \%$ for samples $\mathrm{C}$ and $\mathrm{D}$ and $29 \%$ for sample $\mathrm{E}$ when excluding laboratories 09 and 10 due to insufficient valid results. Again, sample $\mathrm{E}$ is below the LoQ for the dilution series used for samples S, A and B, thereby contributing to the higher intra- and inter-laboratory

Table 4: Geometric mean estimated concentration $(\mu \mathrm{g} / \mathrm{mL})$ based on laboratory-reported estimates.

\begin{tabular}{|c|c|c|c|c|c|c|c|c|c|c|c|c|c|c|c|c|c|c|}
\hline \multirow[t]{2}{*}{ Lab code } & \multicolumn{3}{|c|}{ Sample S } & \multicolumn{3}{|c|}{ Sample A } & \multicolumn{3}{|c|}{ Sample B } & \multicolumn{3}{|c|}{ Sample C } & \multicolumn{3}{|c|}{ Sample D } & \multicolumn{3}{|c|}{ Sample E } \\
\hline & $\mathbf{G M}^{\mathrm{a}}$ & $\% \mathbf{G C V}^{\mathbf{b}}$ & $n^{c}$ & GM & $\%$ GCV & $n$ & GM & $\%$ GCV & $\mathbf{n}$ & GM & $\%$ GCV & $\mathbf{n}$ & GM & $\%$ GCV & $\mathbf{n}$ & GM & $\%$ GCV & $\mathbf{n}$ \\
\hline 01 & 6.718 & 7.230 & 6 & 10.921 & 3.538 & 6 & 7.245 & 3.904 & 6 & 0.515 & 1.888 & 6 & 0.079 & 1.595 & 6 & 0.005 & 5.606 & 6 \\
\hline 02 & 5.532 & 2.223 & 6 & 9.980 & 1.340 & 6 & 6.176 & 1.309 & 6 & 0.551 & 1.132 & 6 & 0.074 & 1.951 & 6 & 0.004 & 2.054 & 6 \\
\hline 03 & 7.177 & 1.315 & 6 & 12.620 & 1.705 & 6 & 9.318 & 3.026 & 6 & 0.764 & 1.960 & 6 & 0.117 & 1.932 & 6 & 0.008 & 2.249 & 6 \\
\hline 04 & 7.584 & 3.358 & 6 & 11.852 & 4.472 & 6 & 10.810 & 5.712 & 6 & 0.673 & 2.465 & 6 & 0.100 & 2.702 & 6 & 0.006 & 6.606 & 6 \\
\hline $05 a$ & 8.719 & 2.691 & 6 & 14.309 & 2.602 & 6 & 11.753 & 3.202 & 6 & 0.863 & 3.092 & 6 & 0.113 & 4.144 & 6 & 0.008 & 2.315 & 6 \\
\hline $05 b$ & 7.935 & 5.637 & 6 & 13.298 & 4.047 & 6 & 10.753 & 4.132 & 6 & 0.747 & 3.033 & 6 & 0.105 & 3.557 & 6 & 0.008 & 3.219 & 6 \\
\hline 06 & 6.320 & 2.091 & 6 & 10.990 & 1.249 & 6 & 8.040 & 1.770 & 6 & 0.675 & 1.445 & 6 & 0.098 & 0.471 & 6 & 0.007 & 11.614 & 6 \\
\hline 07 & 6.792 & 5.234 & 6 & 10.981 & 2.319 & 6 & 8.011 & 1.393 & 6 & 0.593 & 10.089 & 6 & 0.075 & 3.604 & 6 & 0.005 & 5.690 & 6 \\
\hline 08 & 9.041 & 1.981 & 6 & 15.038 & 2.253 & 6 & 11.375 & 2.824 & 6 & 0.610 & 2.240 & 6 & 0.087 & 2.201 & 6 & 0.010 & 14.231 & 6 \\
\hline 09 & 7.575 & 1.020 & 3 & 12.737 & 0.387 & 3 & 10.011 & 2.802 & 3 & 0.840 & 5.616 & 3 & 0.122 & 3.828 & 3 & 0.008 & 7.037 & 3 \\
\hline 10 & 11.858 & 2.788 & 6 & 19.430 & 7.191 & 6 & 11.148 & 4.070 & 6 & 0.558 & 3.640 & 6 & 0.066 & 9.428 & 6 & 0.004 & 14.604 & 6 \\
\hline 11 & 11.485 & 1.778 & 6 & 18.940 & 3.654 & 6 & 14.178 & 2.349 & 6 & 0.707 & 2.331 & 6 & 0.109 & 1.772 & 6 & 0.008 & 7.139 & 6 \\
\hline 12 & 6.192 & 3.820 & 6 & 11.354 & 3.315 & 6 & 8.487 & 2.531 & 6 & 0.673 & 4.696 & 6 & 0.092 & 4.807 & 6 & 0.008 & 21.711 & 6 \\
\hline All & 7.722 & 25.611 & 13 & 12.989 & 23.123 & 13 & 9.564 & 25.676 & 13 & 0.666 & 17.472 & 13 & 0.094 & 21.739 & 13 & 0.007 & 34.315 & 13 \\
\hline All $^{d}$ & 7.439 & 22.874 & 11 & 12.544 & 20.356 & 11 & 9.393 & 27.694 & 11 & 0.663 & 16.224 & 11 & 0.094 & 17.890 & 11 & 0.007 & 30.878 & 11 \\
\hline
\end{tabular}

${ }^{a} \mathrm{GM}$, geometric mean; ${ }^{b} \mathrm{GCV}$, geometric coefficient of variation; ${ }^{c} n$, number of valid results; ${ }^{\mathrm{d}}$ excluding Lab 09 and Lab 10 . 
Table 5: Geometric mean potency estimates ( $\mu \mathrm{g} /$ ampoule) relative to Sample S calculated at NIBSC.

\begin{tabular}{|c|c|c|c|c|c|c|c|c|c|c|c|c|c|c|c|}
\hline \multirow[t]{2}{*}{ Lab code } & \multicolumn{3}{|c|}{ Sample A } & \multicolumn{3}{|c|}{ Sample B } & \multicolumn{3}{|c|}{ Sample C } & \multicolumn{3}{|c|}{ Sample D } & \multicolumn{3}{|c|}{ Sample E } \\
\hline & $\mathbf{G M}^{\mathrm{a}}$ & $\% \mathbf{G C V}^{\mathbf{b}}$ & $n^{c}$ & GM & $\%$ GCV & $\mathbf{N}$ & GM & $\%$ GCV & $\mathrm{n}$ & GM & $\%$ GCV & $\mathbf{n}$ & GM & $\%$ GCV & $n$ \\
\hline 01 & 10.226 & 2.760 & 6 & 7.083 & 4.971 & 6 & 0.507 & 5.823 & 6 & 0.081 & 8.048 & 6 & 0.006 & 12.126 & 6 \\
\hline 02 & 11.235 & 1.366 & 6 & 7.107 & 1.513 & 6 & 0.640 & 1.763 & 6 & 0.092 & 3.375 & 6 & 0.007 & 6.374 & . \\
\hline 03 & 11.092 & 2.758 & 6 & 8.189 & 2.642 & 6 & 0.671 & 1.149 & 6 & 0.101 & 1.455 & 6 & 0.006 & 1.197 & 6 \\
\hline 04 & 9.632 & 4.640 & 5 & 8.863 & 5.101 & 6 & 0.534 & 3.621 & 6 & 0.078 & 8.699 & 6 & 0.004 & 13.868 & 6 \\
\hline $05 a$ & 10.354 & 1.838 & 6 & 8.522 & 3.597 & 6 & 0.604 & 3.864 & 6 & 0.083 & 3.098 & 6 & 0.005 & 2.655 & 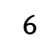 \\
\hline $05 b$ & 10.554 & 2.211 & 6 & 8.526 & 2.566 & 6 & 0.597 & 3.859 & 5 & 0.084 & 7.284 & 6 & 0.007 & 3.910 & 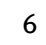 \\
\hline 06 & 10.900 & 1.595 & 6 & 7.967 & 1.487 & 6 & 0.672 & 1.908 & 6 & 0.097 & 1.710 & 6 & 0.008 & 9.469 & 6 \\
\hline 07 & 10.199 & 3.043 & 6 & 7.434 & 4.750 & 6 & 0.525 & 13.048 & 5 & 0.068 & 5.473 & 6 & 0.004 & 17.126 & 6 \\
\hline 08 & 10.469 & 4.250 & 5 & 7.886 & 1.938 & 5 & 0.412 & $\mathrm{n} / \mathrm{a}$ & 2 & 0.060 & 3.210 & 5 & 0.006 & 21.898 & 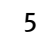 \\
\hline 09 & 10.545 & $\mathrm{n} / \mathrm{a}^{\mathrm{e}}$ & 2 & 8.157 & $\mathrm{n} / \mathrm{a}$ & 2 & 0.846 & 5.970 & 3 & 0.144 & 6.269 & 3 & 0.012 & 11.935 & 3 \\
\hline 10 & 9.356 & $\mathrm{n} / \mathrm{a}$ & 1 & 6.003 & $n / a$ & 2 & 0.309 & 9.046 & 3 & 0.036 & 13.064 & 4 & 0.002 & 42.825 & 4 \\
\hline 11 & 10.233 & 2.322 & 6 & 7.749 & 1.443 & 6 & 0.373 & 3.144 & 6 & 0.060 & 2.587 & 6 & 0.004 & 7.927 & 6 \\
\hline 12 & 11.022 & 3.454 & 4 & 8.376 & 1.316 & 4 & 0.673 & 5.684 & 3 & 0.095 & 4.573 & 5 & 0.009 & 11.316 & 5 \\
\hline All & 10.434 & 5.470 & 13 & 7.798 & 11.014 & 13 & 0.548 & 31.922 & 13 & 0.079 & 39.473 & 13 & 0.006 & 52.324 & 13 \\
\hline All $^{d}$ & 10.528 & 4.706 & 11 & 7.953 & 7.790 & 11 & 0.555 & 22.206 & 11 & 0.081 & 20.283 & 11 & 0.006 & 28.982 & 11 \\
\hline
\end{tabular}

${ }^{\mathrm{a}} \mathrm{GM}$, geometric mean; ${ }^{\mathrm{b}} \mathrm{GCV}$, geometric coefficient of variation; $\mathrm{c} n$, number of valid results; ${ }^{\mathrm{d}}$ excluding Lab 09 and Lab $10 ;{ }^{e} \mathrm{n} / \mathrm{a}$, not calculated as $\mathrm{n}<3$.

variability for this sample. Laboratories 09 and 10 have been excluded from the final inter-laboratory GM and GCV calculations because of insufficient valid results. For comparison, Tables 4-6 present the data including and excluding Laboratories 09 and 10.

Table 7 summarizes inter-laboratory variability and shows inter-laboratory variability is independent of the standard used for samples C and D. Sample E has been excluded because it is below the LoQ.

\section{Potencies of samples $A$ and $B$ relative to the 3rd IS}

There was better overall agreement between all laboratories and between assay methods for the potency of sample A (19/118), the candidate 4th International Standard, than for sample B (19/162). Summary statistics of concentration estimates for samples A and B relative to sample $S$ are shown in Supplementary Table 3. The overall geometric mean potency for sample A is $10.5 \mu \mathrm{g} /$ ampoule with expanded uncertainty limits 10.2-10.8 $\mu \mathrm{g}$ /ampoule.

\section{Potencies for samples B-E relative to the candidate 4th International Standard for Ferritin (Human Recombinant), 19/118}

Table 6 shows the concentration estimates for samples $\mathrm{B}-\mathrm{E}$ relative to sample A, based on the potency of
$10.5 \mu \mathrm{g} /$ ampoule. We suggest that sample $\mathrm{B}$ can be distributed and used as an internal assay/run control.

\section{Stability}

Estimates of the potency for ampoules of samples A $(19 / 118)$ and B (19/162) stored at elevated temperatures for a period of 2.0 and 1.7 years respectively are summarised in Supplementary Tables 4 and 5. The analysis has shown a predicted loss of potency per year of $0.01 \%$ for $19 / 118$ and $0.02 \%$ for $19 / 162$ when stored at $-20{ }^{\circ} \mathrm{C}$. We can be confident that $19 / 118$ and 19/162 will be stable for decades when stored at $-20{ }^{\circ} \mathrm{C}$ and are suitable for shipment at ambient temperature.

\section{Discussion}

An International Standard for Ferritin was originally developed during the 1980s, in response to the expanding number of commercial assays available for quantifying Ferritin and was coordinated by the International Committee for Standardization in Haematology (Expert Panel on Iron) [8], leading to the establishment of the 1st IS for Ferritin. See Thorpe [15] for a full review on the role of international biological reference materials in the diagnosis of anaemia. Nowadays, the vast majority of Ferritin assays are performed using automated assay platforms and for this study, 11 of the 12 participating laboratories 
A)

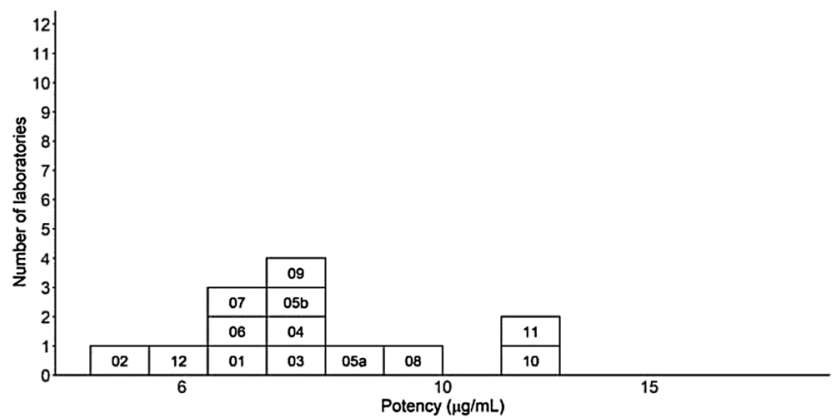

B)

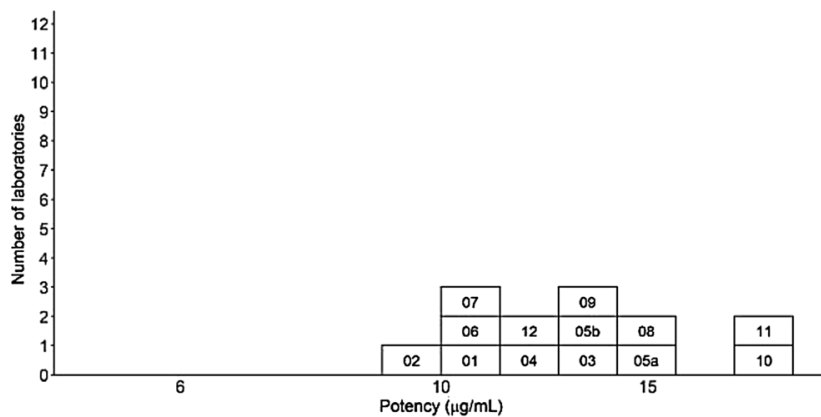

D)

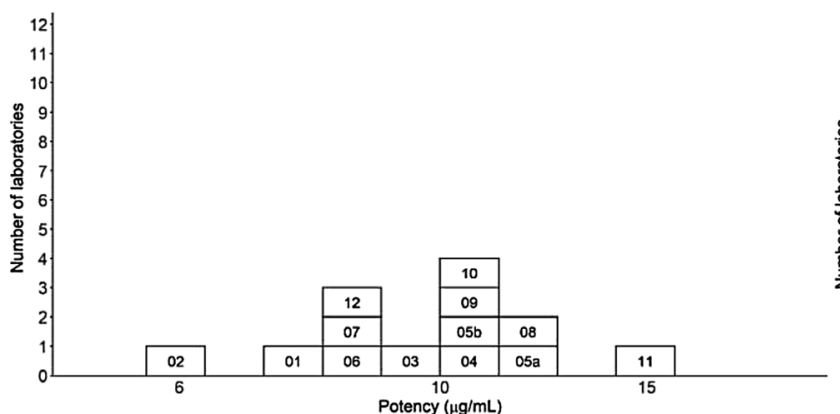

C)

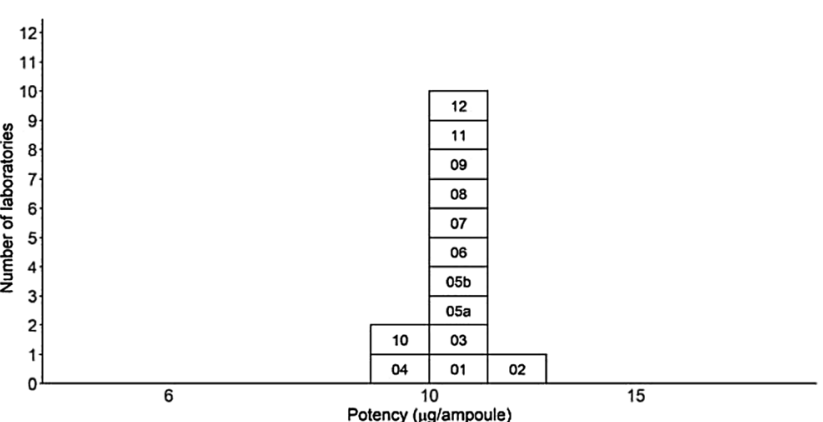

E)

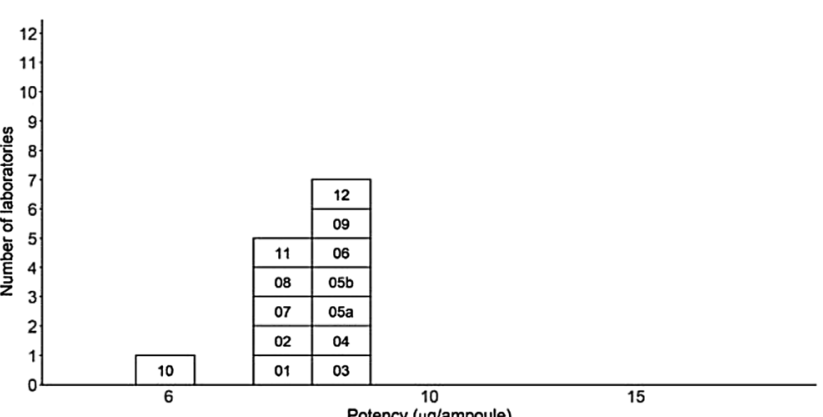

Figure 1: Concentrations based on laboratory-reported estimates and potency estimates relative to sample S (WHO 3rd IS for Ferritin). (A) Concentrations of sample $\mathrm{S}$ based on laboratory-reported estimates. (B) Concentrations of sample A based on laboratory-reported estimates. (C) Potency estimates of sample A relative to sample S. (D) Concentrations of sample B based on laboratory-reported estimates. (E) Potency estimates of sample B relative to sample S. (F) Concentrations of sample C based on laboratory-reported estimates. (G) Potency estimates of sample $C$ relative to sample $S$. (H) Concentrations of sample D based on laboratory-reported estimates. (I) Potency estimates of sample D relative to sample S. (J) Concentrations of sample E based on laboratory-reported estimates. (K) Potency estimates of sample $E$ relative to sample S. Estimates are expressed on a log scale. The number in the square denotes the laboratory code. Each square represents the geometric mean estimate from that laboratory. 
F)

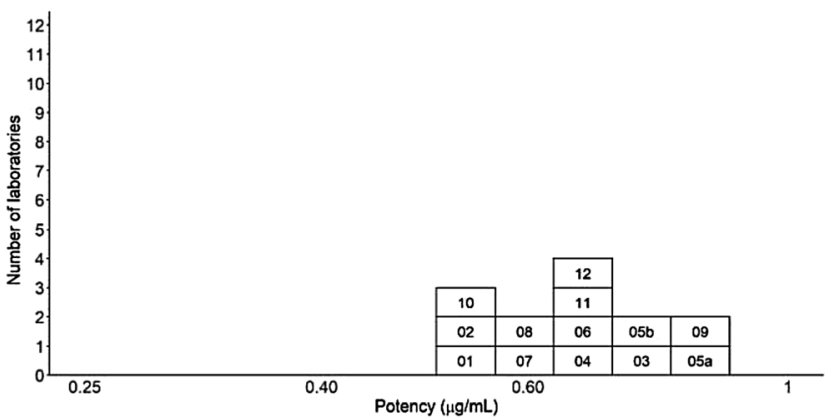

H)

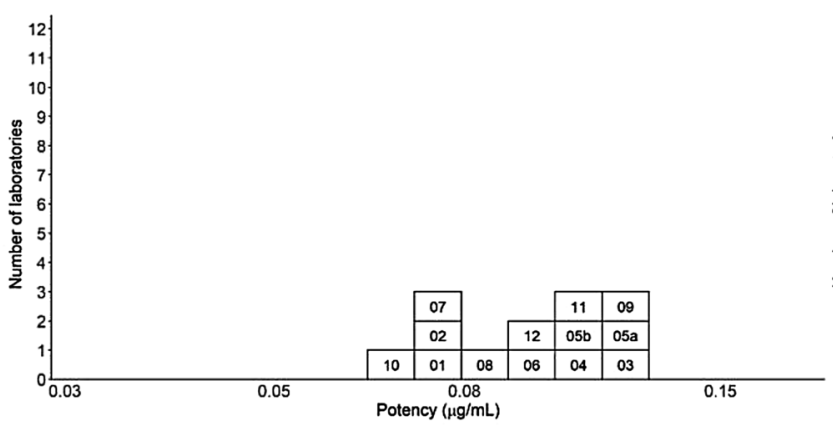

J)

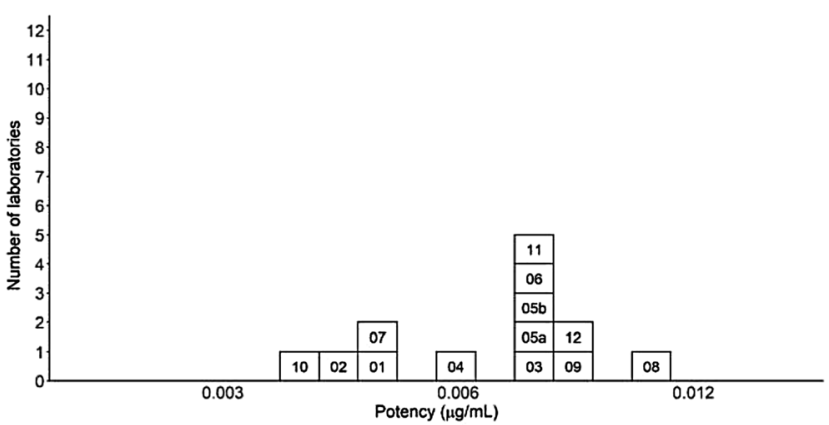

Figure 1: Continued.

performed Ferritin quantitation using automated assay platforms and one laboratory used a manual ELISA kit. Indeed, a recent review and meta-analysis of accuracy and comparability of Ferritin methods has shown that the most widely used methods included radiometric, nonradiometric and agglutination assays. The intra-run imprecision for the most reported Ferritin methods was $6.2 \pm 3.4 \%$ and inter-run imprecision $8.9 \pm 8.7 \%$ [16].

The concentration of serum Ferritin provides guidance for the clinician in the diagnosis of iron deficiency [17] and overload [18]. Current tests are reasonably accurate for diagnosing iron deficiency when a patient seeks medical attention and where the clinician suspects iron deficiency,

\section{G)}

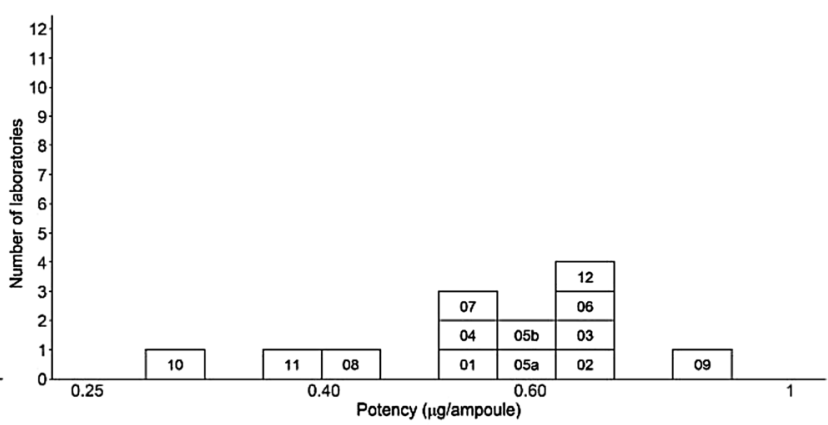

I)

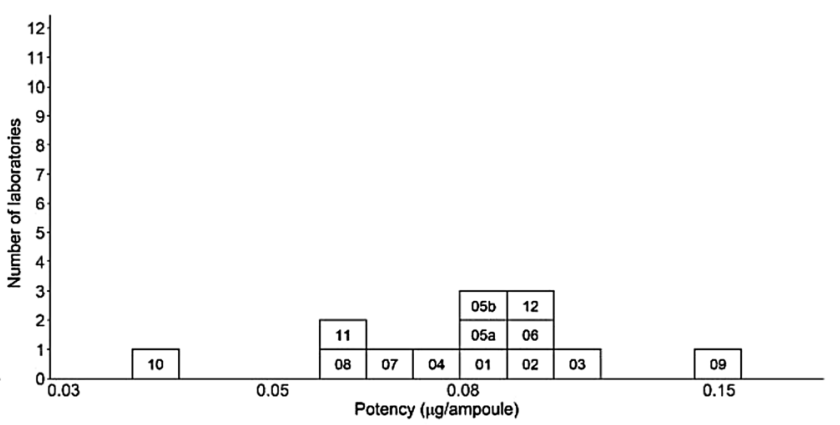

K)

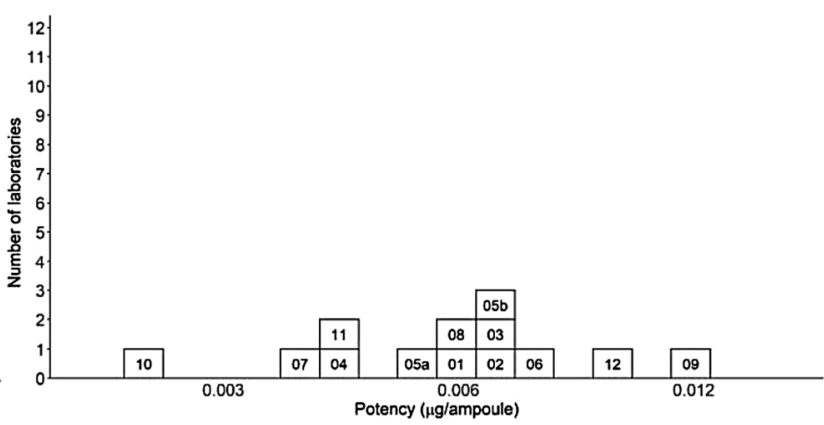

but there is insufficient evidence for diagnosing iron overload. For example, in studies where people with less than $30 \mu \mathrm{g} / \mathrm{L}$ of serum Ferritin were diagnosed with iron deficiency, Ferritin blood tests correctly identified iron deficiency in four out of five people who did have iron deficiency; and no iron deficiency in 19 out of 20 people who had normal levels of iron. It should be borne in mind that Ferritin levels can be difficult to interpret if infection or inflammation is present, as levels can be high even in the presence of iron deficiency. Ferritin levels are also increased independently of iron status in acute and chronic inflammatory conditions, malignant disease, and liver disease. Further studies are required, to strengthen the 
Table 6: Geometric mean potency estimates ( $\mu \mathrm{g} /$ ampoule) relative to Sample A calculated at NIBSC.

\begin{tabular}{|c|c|c|c|c|c|c|c|c|c|c|c|c|}
\hline \multirow[t]{2}{*}{ Lab code } & \multicolumn{3}{|c|}{ Sample B } & \multicolumn{3}{|c|}{ Sample C } & \multicolumn{3}{|c|}{ Sample D } & \multicolumn{3}{|c|}{ Sample E } \\
\hline & $\mathbf{G M}^{\mathrm{a}}$ & $\% G_{C V}^{b}$ & $n^{c}$ & GM & $\%$ GCV & $n$ & GM & $\%$ GCV & $n$ & GM & $\%$ GCV & $\mathbf{n}$ \\
\hline 01 & 7.302 & 4.788 & 6 & 0.521 & 4.970 & 6 & 0.085 & 7.204 & 6 & 0.006 & 10.877 & 6 \\
\hline 02 & 6.652 & 1.530 & 6 & 0.591 & 1.804 & 6 & 0.084 & 5.776 & 6 & 0.006 & 10.741 & 6 \\
\hline 03 & 7.755 & 4.871 & 6 & 0.637 & 1.946 & 6 & 0.096 & 2.203 & 6 & 0.006 & 1.832 & 6 \\
\hline 04 & 9.574 & 5.401 & 5 & 0.589 & 4.784 & 5 & 0.088 & 5.179 & 5 & 0.005 & 12.503 & 5 \\
\hline $05 a$ & 8.638 & 2.585 & 6 & 0.614 & 2.969 & 6 & 0.084 & 2.410 & 6 & 0.005 & 3.218 & 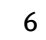 \\
\hline $05 \mathrm{~b}$ & 8.484 & 1.031 & 6 & 0.593 & 3.295 & 5 & 0.083 & 6.614 & 6 & 0.006 & 3.203 & . \\
\hline 06 & 7.671 & 2.291 & 6 & 0.649 & 2.077 & 6 & 0.093 & 1.461 & 6 & 0.007 & 8.825 & 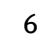 \\
\hline 07 & 7.687 & 1.910 & 6 & 0.554 & 11.916 & 5 & 0.074 & 2.860 & 6 & 0.004 & 11.061 & 6 \\
\hline 08 & 7.936 & 3.363 & 6 & 0.395 & $n / a$ & 2 & 0.061 & 3.485 & 6 & 0.007 & 10.764 & 6 \\
\hline 09 & 7.630 & $\mathrm{n} / \mathrm{a}^{\mathrm{e}}$ & 1 & 0.806 & $\mathrm{n} / \mathrm{a}$ & 2 & 0.143 & $\mathrm{n} / \mathrm{a}$ & 2 & 0.013 & $\mathrm{n} / \mathrm{a}$ & 2 \\
\hline 10 & 6.795 & $\mathrm{n} / \mathrm{a}$ & 1 & $N P^{f}$ & $n / a$ & $n / a$ & 0.037 & $\mathrm{n} / \mathrm{a}$ & 1 & 0.003 & $\mathrm{n} / \mathrm{a}$ & 1 \\
\hline 11 & 7.954 & 3.363 & 6 & 0.394 & $\mathrm{n} / \mathrm{a}$ & 2 & 0.065 & 2.301 & 6 & 0.005 & 7.170 & 6 \\
\hline 12 & 8.039 & 4.679 & 3 & 0.631 & 6.264 & 3 & 0.089 & 6.649 & 5 & 0.008 & 19.135 & 5 \\
\hline All & 7.821 & 10.081 & 13 & 0.570 & 22.432 & 12 & 0.080 & 35.947 & 13 & 0.006 & 39.319 & 13 \\
\hline All $^{\mathrm{d}}$ & 7.940 & 9.823 & 11 & 0.553 & 19.607 & 11 & 0.082 & 15.349 & 11 & 0.006 & 19.498 & 11 \\
\hline
\end{tabular}

${ }^{a} \mathrm{GM}$, geometric mean; ${ }^{\mathrm{b}} \mathrm{GCV}$, geometric coefficient of variation; ${ }^{\mathrm{c}} \mathrm{n}$, number of valid results; ${ }^{\mathrm{d}}$ excluding Lab 09 and Lab 10; ${ }^{\mathrm{e}} \mathrm{n} / \mathrm{a}$, not calculated as $\mathrm{n}<3 ;{ }^{\mathrm{f}} \mathrm{NP}$, non-parallel.

Table 7: Summary of inter-laboratory \%GCV (excluding Lab 09 and Lab 10).

\begin{tabular}{lrrrr}
\hline Standard & \multicolumn{4}{c}{ Test sample } \\
\cline { 2 - 5 } & Sample A & Sample B & Sample C & Sample D \\
\hline Sample S & $5 \%$ & $8 \%$ & $22 \%$ & $20 \%$ \\
In-house & $20 \%$ & $28 \%$ & $16 \%$ & $18 \%$ \\
Sample A & - & $10 \%$ & $20 \%$ & $15 \%$ \\
Sample B & $10 \%$ & - & $22 \%$ & $21 \%$ \\
\hline
\end{tabular}

evidence, using a broader range of populations to identify the serum Ferritin levels which best indicate iron deficiency and overload $[2,6,19]$.

Over the past 24 years, the 3rd IS for Ferritin has been available to standardize modern assays and minimise drift through manufacturers adopting a 'harmonisation' approach in which the calibration is adjusted to conform to overall mean values $[15,20]$. Manufacturers standardizing their kit calibrators with traceability to the current IS (highest order standard) ensure compliance with in vitro diagnostic regulations. The authors sincerely hope that widespread use of the 4th IS for the calibration of clinical tests will improve harmonisation and ultimately, improve patient outcomes.

The main purpose of this study was to replace the 3rd IS by showing immunological similarity to either of the candidate replacement standards and to then assign a potency to one candidate based on the combined results from statistically valid assays. In addition, three commutability samples were included in the study and all methods were able to differentiate between low, normal and high levels of Ferritin in the clinical samples. As this is a replacement IS there is no formal requirement for a full commutability assessment which was outside the scope of this study. We have shown that the results from participating laboratories align to a common standard, and like for the 3rd IS [10, 20], adopting the 4th IS to standardize immunoassays will significantly reduce assay drift. Looking forward, it would be beneficial to collect more data on the performance of the 4th IS in a separate study, in collaboration with various external quality assessment (EQA) schemes.

All the participants of this study either agreed with the proposal to adopt sample A (19/118) as the 4th International Standard for Ferritin (Human, Recombinant) or did not express an opinion. Together with the agreement of the scientific advisor and co-ordinator it was recommended to the WHO Expert Committee on Biological Standardization (ECBS) that sample A, 19/118, be established as the 4th International Standard for Ferritin (Human, Recombinant) with an assigned potency of $10.5 \mu \mathrm{g} / \mathrm{ampoule}$ and expanded uncertainty limits 10.2-10.8 $\mu \mathrm{g}$ /ampoule (95\% confidence; $k=2.23)$. The 4th IS was established by WHO ECBS during their annual meeting in October 2021. The 4th IS is available from the NIBSC (www.nibsc.org).

Acknowledgments: We thank the staff of the Standards Processing Division and Standardization Science, NIBSC, for ampouling samples A-E and Min Fang (NIBSC) for MS 
analysis of the candidate samples. We also thank all the participants of the collaborative study.

Research funding: None declared.

Author contributions: BF, GR and $\mathrm{CB}$ prepared and evaluated the candidate samples; EA and PR carried out the statistical analysis; BF led the study, reviewed the results and drafted the manuscript, which was critically reviewed and approved by all of the authors. All authors have accepted responsibility for the entire content of this manuscript and approved its submission.

Competing interests: Authors state no conflict of interest. Informed consent: Not applicable.

Ethical approval: Not applicable.

\section{References}

1. Arosio P, Elia L, Poli M. Ferritin, Cellular iron storage and regulation. IUBMB Life 2017;69:414-22.

2. Kell DB, Pretorius E. Serum Ferritin is an important inflammatory disease marker, as it is mainly a leakage product from damaged cells. Metallomics 2014;6:748-73.

3. Worwood M. Serum Ferritin. Clin Sci (Lond). 1986;70:215-20.

4. Worwood M. Indicators of the iron status of populations: Ferritin. In: WHO, CDC. Assessing the iron status of populations: Report of a Joint World Health Organization/Centers for Disease Control and Prevention technical consultation on the assessment of iron status at the population level, 2nd ed. Geneva: World Health Organization; 2007:35-74 pp. Available from: http://www.who.int/nutrition/publications/micronutrients/ anaemia_iron_deficiency/9789241596107.pdf.

5. WHO. Serum Ferritin concentrations for the assessment of iron status and iron deficiency in populations. In: Vitamin and mineral nutrition information system. Geneva: World Health Organization; 2011. Available from: http://www.who.int/vmnis/ indicators/serum_Ferritin.pdf [Accessed Nov 2021].

6. WHO. WHO guideline on use of Ferritin concentrations to assess iron status in individuals and populations. Geneva: World Health Organization; 2020.

7. Preparation, characterization and storage of human Ferritin for use as a standard for the assay of serum Ferritin. International Committee for Standardization in Haematology (Expert Panel on Iron). Clin Lab Haematol 1984;6:177-91.
8. Proposed international standard of human Ferritin for the serum Ferritin assay. International Committee for Standardization in Haematology (Expert Panel on Iron). Br J Haematol 1985;61:61-3.

9. WHO. Expert Committee on Biological Standardization. In: World Health Organisation Technical Report Series. Geneva: World Health Organization; 1994:1-218 pp.

10. Thorpe SJ, Walker D, Arosio P, Heath A, Cook JD, Worwood M. International collaborative study to evaluate a recombinant L Ferritin preparation as an International Standard. Clin Chem 1997;43:1582-7.

11. Levi S, Corsi B, Rovida E, Cozzi A, Santambrogio P, Albertini A, et al. Construction of a ferroxidase center in human Ferritin L-chain. J Biol Chem 1994;269:30334-9.

12. Levi S, Santambrogio P, Cozzi A, Rovida E, Corsi B, Tamborini E, et al. The role of the L-chain in Ferritin iron incorporation. Studies of homo and heteropolymers. J Mol Biol 1994;238:649-54.

13. R Core Team. R: A language and environment for statistical computing. Vienna, Austria: R Foundation for Statistical Computing. Available from: https://wwwR-projectorg/. 2021.

14. Kirkwood TB. Predicting the stability of biological standards and products. Biometrics 1977;33:736-42.

15. Thorpe SJ. The development and role of international biological reference materials in the diagnosis of anaemia. Biologicals 2010;38:449-58.

16. Garcia-Casal MN, Peña-Rosas JP, Urrechaga E, Escanero JF, Huo J, Martinez RX, et al. Performance and comparability of laboratory methods for measuring Ferritin concentrations in human serum or plasma: a systematic review and meta-analysis. PLoS One 2018;13:e0196576.

17. Daru J, Allotey J, Peña-Rosas JP, Khan KS. Serum Ferritin thresholds for the diagnosis of iron deficiency in pregnancy: a systematic review. Transfus Med 2017;27:167-74.

18. Koperdanova M, Cullis JO. Interpreting raised serum Ferritin levels. BMJ 2015;351:h3692.

19. Garcia-Casal MN, Pasricha SR, Martinez RX, Lopez-Perez L, PeñaRosas JP. Serum or plasma Ferritin concentration as an index of iron deficiency and overload. Cochrane Database Syst Rev 2021;5: CD011817.

20. Blackmore S, Hamilton M, Lee A, Worwood M, Brierley M, Heath A, et al. Automated immunoassay methods for Ferritin: recovery studies to assess traceability to an International Standard. Clin Chem Lab Med 2008;46:1450-7.

Supplementary Material: The online version of this article offers supplementary material (https://doi.org/10.1515/cclm-2021-1139). 